The prompt recovery in this case of the power of rolition over the tibialis anticus is highly instructive in the study of the rtiology of congenital talipes equinus, and, indeed, of club-foot in general.

In the commencement of my investigations into these diseases, I supposed, as I believe it has been the opinion of the few who bave thought upon the subject, that the debility of the anterior muscles of the leg was solely the result of the long-continued over-action of the powerful antagonist muscles, mechanically stretching them, and physically altering the muscular fibres. That the latter does take place to a certain extent is proved by this case, as she was unable to bend the ankle at first; but we see that although the anterior tibial muscle had been mechanically stretched to its ntmost possible extent nearly twenty years, on the restoration of the ankle-joint to its proper motion, a few weeks time sufficed for the complete recovery of its power; whereas in other cases, where the same muscle was primarily involved, and which I have watched two years after their cure, by division of the tendo Achillis, I have not perceived that the paralysed muscle has recovered aught of its natural power, although it produced scarcely any impediment to the walking.-(Vide LANcET, March 31, 1838, p. 16).

At the present time she is able to walk or dance, as if the limb had never been contracted.

\section{EFFECTS OF FRIGHT ON THE NERVOUS SYSTEM.}

\section{To the Editor of The LANCET.}

SIR:-If you think the following case sufficiently interesting for insertion in your Journal, I hope it will call forth some physiological remarks. I am, Sir, your obedient servant,

East Retford, May 15, 1838.

$$
\text { Wim. Allison. }
$$

Catherine Bower, a pale, delicate-looking girl (a kitchen-maid), aged 16, who had menstruated properly, had a fright in May, 1836. The other servants agreed (unknown to Bower) to alarm her by representing a ghost. The representation was managed skilfully, and the girl was surprised and exceedingly agitated. General tremor, with palpitation of the heart, was the conse. quence; so that she must have had a sudden and violent shock. During some months afterwards she often felt alarmed, with a fluttering at her heart and stomach.

Oct. 12, 1836. I was desired to see her; she complained of frequent romiting, and of being unable to retain any food; with occasional pain at her stomach, for which she took-
Comp. ext. of colocynth, with calomel;

Rust of iron, with rhubarb and soda.

13. Had sonorous breathing (occasionally on both expiration and inspiration), more particularly so when she laughed; for then the breathing became quicker, louder, and more involuntary. The noise was not constant. She had pain in her trachea when she langhed, or when the noise was louder.

Calomel, ten grains; and a purging draught.

14. The breathing became louder, and the noise more constant, with continued pain in the trachea.

V.S. $\overline{5} \times x$. (buffy); hydrocyanic acid; uccasional active purges.

She gradually improved until the 21st, when all the symptoms increased.

V.S. $3 \times x x$. (cupped and buffy); hydro. cyunic acid ; occasional purges.

24. Gradually improving; the romiting has ceased.

Iodine; purges continued.

The girl had recovered at the end of the month, after repeated doses of calomel pills with draughts or castor-oil.

Dec. 20. Loud and painful breathing re. turned (perhaps from a cold).

V.S. 3xx. (not cupped nor bufry); calomel and opening draught.

21. The girl was seen by Dr. Scholfield, of Doncaster (who has since inquired after "the girl with the musical trachea"). He wished me then, to begin treating the complaint more as a nervous than as an iniammatory affection; but he recommended leeches, nauseating doses of antimony with calomel, a succession of small blister's about the throat, and general bleeding, if it be. came absolntely necessary.

23. Symptoms increased.

V.S. $3 \times x \times y$. (cupped and buffy); active purges.

The girl soon recovered.

June, 1837. The girl's master and mis. tress being from home, the other servants determined to try the effect of another friglst, thinking that her first illness had not been produced by such a cause. On a Sunday, when the girl supposed that she was left in care of the house, and was making beds, one of the bedroom bells was made to ring, and that was managed by a contrivance which the girl could not discover, so that she became very much alarmed and agitated. The noisy, painful breathing came on.

V.S. $5 x x x$. (not buffy); active purges.

She soon recovered, and since that time has had very good health.

May, 1838. I have seen the girl this week, who told me that she never felt right between the time of her first fright and of her first serious illness; that she is sure the second fright brought on her last illness; and that she felt immediate and considerable relief after every bleeding.

She once missed having a monthly dis. 
charge, viz., after the first fright, and betore the first serious illness.

The pulse was generally quick and soft, but when she had pain in her throat, there was a sharpness in the beat. On two occasions she took a quarter of a grain of muriate of morphia, without any apparent benefit.

It is generally believed that tumours have been cured by having been gently stroked with the hand of a dead man who had been hanged,-that terror has stinulated the absorbents. In the cuse of Bower, the following questions arise :-

1st. Did the fright occasion an irregular and unusual supply of nervous infuence to certain branches of nerves?

2nd. Did those branches distributed about the trachea become so energetic as to set up irritation and inflammatory action in the blood-vessels after the second fright? or, rather,

3rd. Is it possible that the fright might have occasioned inflammation about the trichea if the girl had nut been bled?

4th. Could there be so much inflammation about the trachea (with such slight symp. toms) on the 23rd of September, 1836, us to occasion the cupped appearance of the blood?

5th. Or conld the cupped appearance be occasioned by nervous influence on the blood-vessels?

6th. What other plan of treatment would have answered better?

The first inflammatory action cannot be connected satisfactorily with the first fright, and yet the latter might have produced a predisposition to the former. Inflammation appeared to be a very probable consequence of the second fright, if the affection produced had been left to nature.

I have merely related facts as they occurred; and any opinions upon them will be read by me with interest.

\section{A CASE OK}

\section{PES EQUINUS CURED BY DIVIDTNG THE TENDO ACHILLIS.}

By Dr. Gustaves Krauss, London.

\section{(Read before the Medical and Chirurgical Society.)}

G. Bocock, a boy of 17 years of age, in consequence of external injury became affected with an extensive abscess on the calf of the left leg. The mischief extended over the whole of the leg and thigh. He entered St. Bartholomew's Hospital, and was discharged cured after a stay of six teen weeks in the hospital. The knee, which had been kept in the bent position during the cure of the abscesses, gradually became extended, but the retraction of the heel still remained when the patient placed himself under my care.
The dorsum of the foot was nearly in a line with the tibia at that time, the articulating surface of the astragalus being very prominent, and the heel being entirely drawn up. The patient walked upon the toes, resting upon the anterior extremities of the metatarsal bones, and the foot offered a true example of pes equinus in a high degree. On the internal side of the gastrocnemii muscles a tight and hard cord existed; the knee conld not entirely be straightened; it formed a slight curre, the tendous of the semi-membranosus and semitendinosus muscles forming a very promi. nent cord behind it. A cicatrix extended over the back of the leg and the lower part of the thigh.

Dec. 4, 183\%. The tento Achillis was divided by means of a convex knife. The blade was inserted in front of the tendon with the eage directed towards it so as to cut through it from before backwards, with. out dividing the sheath or the skin behind it. The foot was maintained in a position farourable to the union of the divided ten. dou by the instrument intended subsequently to effcct the extension.

6. The wound was healed, neither Iocal inflammation nor any symptom of constitutional irritation having taken place. The space between the two ends of the tendon can be distinguished by its softness and by its livid colom. 1 began with precantion the extension of the foot.

10. The foot forms with the leg an angle of about $110^{\circ}$. The intermediate substance seems pretty strong but thinner than the ends of the divided tendon.

13. The foot forms a right angle with the leg, and the articulating surface of the astra. galus has recovered its natural positiou opposite to the articulating surface of the tibia.

16. The patient began to walk supported by another person.

20. The foot can now be bent to an angle less than a right angle. Some odematous swelling has taken place on the foot, extending over the ankles, and also enrelop. ing the tendo Achillis. For the last two days the patient has left his bed.

25. The oedematous swelling somewhat diminished. He walks better.

Jan. 24. The ocdematous swelling entirely removed. The intermediate substance can be distinguished by its smaller volume. The patient walks well with a stick, but he rests the point of the foot at first on the ground, and the heel afterwards. The left inferior extremity is about an inch and a half shorter than the other.

Since the beginning of February the pan tient wears his instrument only at night. He walks now without the aid of a stick a distance of three miles and more. The curve of the knee had much improved. The tendons of the semi-tendinosus and semi- 